\title{
Determination of Copper and Lead and Study their Poisonous Effects in Drinking Water in Baghdad
}

\author{
Thkra A. Hassen* \\ Received 18, February, 2013 \\ Accepted 17, June, 2013
}

\begin{abstract}
:
The objective of this study is to determine the concentration of copper and lead $(\mathrm{mg} / \mathrm{L})$ in drinking water by using absorption spectrophotometic and Atomic Absorption spectrophotometric method from different area in Baghdad and with different intervals, The results show that the concentration of copper and Lead ( $\mathrm{mg} \backslash \mathrm{L}$ ) in tap water which remains motionless in plumbing system for following periods one hours, 3 hours, 6 hours, 12 hours, 24 hours, 7 days and 14 days are (1, $2.2,4,5.3,7.5,10$ and $16 \mathrm{mg} \backslash \mathrm{L}$ copper $) \&(0.3,0.5,0.8,1,2.5,3,3.8 \mathrm{mg} / \mathrm{L}$ lead ) respectively .from these results its clear that high levels of copper \& Lead occur if tap water comes in contact with copper - lead plumbing and copper lead containing fixtures in the water distribution system. If tap water remains motionless in the plumbing system for some time.

These amounts of copper and Lead are believed to give rise to the symptoms of chemical food poisoning precipitated by the ingestion of alcohol on an empty stomach ( in presence of copper ). Also children under one year of age are more sensitive to copper than adults. Long-term exposure (more than 14 days) to copper - lead in drinking water which is much higher than 1,000 ug/I has been found to cause kidney and liver damage in infants, In case of Lead it can effect a children physical development \& ability to learn.
\end{abstract}

Key words: Lead determination, Spectrophotometry, 1-(2-pyridylazo)-2-napthol, copper determination.

\section{Introduction:}

Copper and its compounds are common in the environment. The body may be exposed to copper by breathing air, eating food, or drinking water containing copper. Also they can be exposed by skin contact with soil, water, or other copper-containing substances. [1-5] Levels of copper found naturally in ground water and surface water that are generally very low; about 4 micrograms of copper in one liter of water or less. However, drinking water may contain higher levels of a dissolved form of copper. [6].

High levels of copper occur if tap water comes in contact with copper plumbing and copper-containing

fixtures in the water distribution system. If corrosive water remains motionless in the plumbing system for six hours or more, copper levels may exceed 1,000 ug/l[7]. The level of copper in drinking water increases with the corrosivity of the water and the length of time it remains in contact with the plumbing. Copper is necessary for good health. The body got about 1,000 micrograms (1,000 ug) of copper per day by eating and drinking.[8,9] Drinking water normally contributes approximately $150 \mathrm{ug} /$ day. Immediate effects from drinking water which contains elevated levels of copper include vomiting, diarrhea, stomach cramps and nausea, The seriousness of

*Dept. of Basic Science, College of Dentistry, University of Al Mustansiryia 
these effects can be expected to increase with increased copper levels or length of exposure.[10] Children under one year of age are more sensitive to copper than adults. Longterm exposure (more than 14 days) to copper in drinking water which is much higher than $1,000 \mathrm{mg} / \mathrm{L}$ has been found to cause kidney and liver damage in infants. Other persons who are highly susceptible to copper toxicity include people with liver damage or Wilson's disease because copper exhibits these harmful health effects, and because drinking water may be a significant route of exposure to copper,[11-15] it is important to determine the amount of copper in drinking water .

Lead, a metal found in natural deposits, is commonly used in household plumbing materials and water service lines. The greatest exposure to lead is swallowing or breathing in lead paint chips and dust. Lead is rarely found in source water, but enters tap water through corrosion of plumbing materials. Homes built before 1986 are more likely to have lead pipes, fixtures and solder. However, new homes are also at risk: even legally "lead-free" plumbing may contain up to 8 percent lead. The most common problem is with brass or chrome-plated.

Lead in drinking water can cause a variety of adverse health effects. In babies and children, exposure to lead in drinking water above the action level can result in delays in physical and mental development, along with slight deficits in attention span and learning abilities. In adults, it can cause increases in blood pressure. Adults who drink this water over many years could develop kidney problems or high blood pressure.

Atomic absorption spectrophotometric method has been used to determine the amount of the lead in drinking water using an ammonium tetramethylenedithiocarbamate

extraction technigue as separating agent .

Spectrophotometric method has been used to determine the amount of the copper in drinking water in this work; Spectrophotometry is essentially a trace-analysis technique and is one of the most powerful tools in chemical analysis. 1-(2-pyridylazo)-2-naphthol (PAN) [16] has been used for the spectrophotometric determination of copper. This is a sensitive, highly specific spectrophotometric method for the trace determination of copper. The method is based on the reaction of nonabsorbent (PAN) in a slightly acidic solution (0.02-0.4 $\mathrm{mol} \mathrm{L}^{-1}$ ) with copper (II) to produce a highly absorbent red chelate product followed by a direct measurement of the absorbance in an aqueous solution with suitable masking, the reaction can be made highly selective and the reagent blank solution do not show any absorbance.[17-20].<smiles>Oc1ccc2ccccc2c1N=Nc1ccccn1</smiles>

Molecular structure of 1-(2Pyridylazo)-2-naphol (PAN)

Material and Methods: Instrumentation

AA-7000 Atomic Absorption Spectrophotometer ( Shimadzu ) ,wave lengh range $185-900 \mathrm{~nm}$,Lamp type : Hallow - cathode and Deuterium , Lamp : 6 Lamps Turrent, Vaporization flame and lor grapgic furnace .

GBC (Australia) (Model:

Cintral-6) double beam UV/VIS the recording spectrophotometer. Chem. Tech. Anal. (U.K.) (Model-ALPHA 4) atomic absorption spectrophotometer 
equipped with a microcomputer controlled air-acetylene flame at $324.7 \mathrm{~nm}$ was used for comparing the results. (Experimental conditions were: Slit width, $2 \mathrm{~nm}$; lamp current, $3 \mathrm{~mA}$; wavelength, 324.7; flow rate of carrier gases are- air, $6.5 \mathrm{~L} \mathrm{~min}^{-1}$; acetylene, 2 $\mathrm{L}_{\text {min. }}{ }^{-1}$; sample volume, $10 \mu \mathrm{L}$.

All of the chemicals used were of analytical reagent grade or the highest purity available. Doubly distilled deionized water, which is nonabsorbent under ultraviolet radiation, was used throughout.

ammonium

tetramethylenedithiocarbamate .

PAN solution 1- (2-Pyridrylazo)-2naphthol (Aldrich A.C.S) was prepared by dissolving the requisite amount of it in a known volume of distilled deionized water. More dilute solution of the reagent was prepared as required.

\section{Copper (II) standard solution $1.57 \times$ $10^{-2} \mathrm{~mol} \mathrm{~L}^{-1}$}

A $100-\mathrm{mL}$ amount of stock solution (1 mg mL $\mathrm{mg}^{-1}$ ) of $\mathrm{Cu}$ (II) was prepared by dissolving $392.9 \mathrm{mg}$ of copper sulfate pentahydrate $\left(\mathrm{CuSO}_{4} .5\right.$ $\mathrm{H}_{2} \mathrm{O}$ ) in doubly distilled deionized water. Aliquots of this solution were standardized by iodometric titration. Working standard solution was prepared by suitable dilutions of the stock solution.

\section{Procedure}

Drinking water samples were collected in polythene bottles from tap of plumbing system from different regions of Baghdad. After collection, $\mathrm{HNO}_{3} \quad\left(1 \mathrm{~mL} \quad \mathrm{~L}^{-1}\right)$ was added as preservative.

A volume of $0.1-1.0-\mathrm{mL}$ of neutral aqueous solution containing $0.1-70 \mu \mathrm{g}$ of copper (II) in a $10-\mathrm{mL}$ volumetric flask was mixed with a 1:5 to 1:100 fold molar excess of 1-(2pyridylazo)-2-napthol (PAN) reagent solution (preferably $1-\mathrm{mL}$ of $4 \times 10^{-3}$ mol $\mathrm{L}^{-1}$ ) followed by the addition of $0.1-2.0-\mathrm{mL}$ of $0.2 \mathrm{~mol} \mathrm{~L}^{-1}$ sulfuric acid. The mixture was diluted to the mark with deionized water. After 1 min the absorbance was measured at $560 \mathrm{~nm}$ against a corresponding reagent blank. The copper content in an unknown sample (drinking water) was determined using a concurrently prepared calibration graph.(shown down)

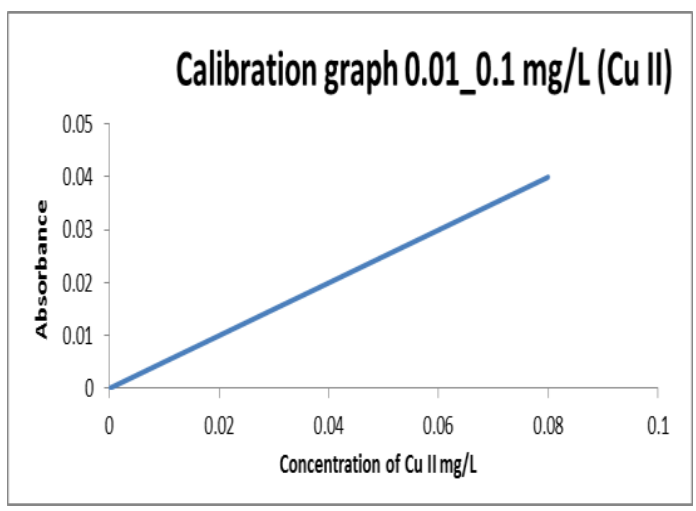

Spectrophotometric analysis in a very dilute solution was derived from Beer's law. Set of solutions were prepared by dilution of stock solution $\left(0.1 \mathrm{mg} \mathrm{L}^{-1}\right)$ to construct the calibration graph, The absorbance of the calibration and sample solutions were measured at wavelength $560 \mathrm{~nm}$, the absorbance to zero was setted with blank deionized water .The straight line equation of calibration graph is $y$ $=\mathrm{mx}+\mathrm{b}$.

The determination of lead in drinking water has been achieved by using semi-micro technigue that chelate and separate the lead into an organic extract (an ammonium tetramethylenedithiocarbamate extraction technigue) prior to analysis, the extract is then injected directly into the atomizer without the need to separate in two phases . 


\section{Result and Discussion:}

Table (1): The relationship between the concentration of copper and Lead $(\mathrm{mg} / \mathrm{L})$ in drinking water and the time remains motionless in plumbing system.

\begin{tabular}{|c|c|c|}
\hline $\begin{array}{c}\text { Tap water } \\
\text { remains } \\
\text { motionless } \\
\text { in } \\
\text { plumbing } \\
\text { system for }\end{array}$ & $\begin{array}{c}\text { Concentration } \\
\text { of copper } \\
(\mathbf{m g} \backslash \mathbf{L}) \text { in } \\
\text { drinking } \\
\text { water }\end{array}$ & $\begin{array}{c}\text { Concentration } \\
\text { of Lead } \\
(\mathbf{m g} \mathbf{L}) \text { in } \\
\text { drinking } \\
\text { water }\end{array}$ \\
\hline 1 hour & 1.0 & 0.3 \\
\hline 3 hours & 2.2 & 0.5 \\
\hline 6 hours & 4.0 & 0.8 \\
\hline 12 hours & 5.3 & 1.0 \\
\hline 1 day & 7.5 & 2.5 \\
\hline 7 days & 10.0 & 3.0 \\
\hline 14 days & 16.0 & 3.8 \\
\hline
\end{tabular}

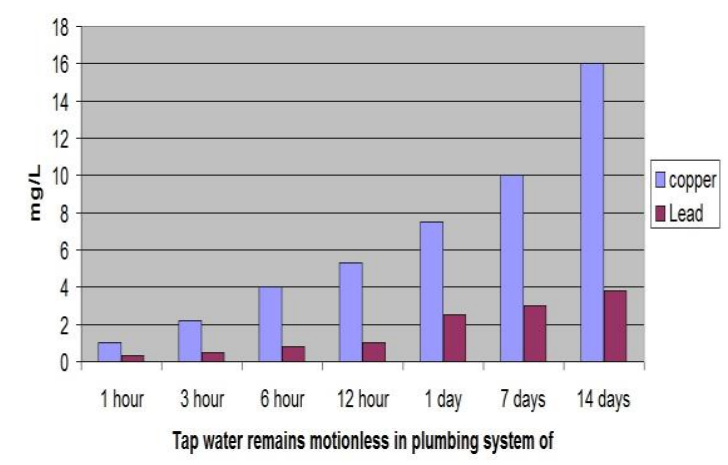

Fig. (1): Histogram between the concentration of copper and lead $(\mathrm{mg} / \mathrm{L})$ in drinking water and the time remains motionless in plumbing system

The determination of copper with 1-(2Pyridylazo)-2-napho can be directly conducted in an aqueous solution without the need for any separations or clean up step. The reaction is instantaneous and the absorbance remains stable for over $72 \mathrm{~h}$. and the useful concentration range (0.01-0.1 $\left.\mu \mathrm{g} \mathrm{mL}^{-1}\right)$ for Beer's low is widened. Finally, with suitable masking, the reaction can be made highly selective and reagent blank solutions do not show any absorbance.

Table (1) and graph (1) show that the concentration of copper and lead $(\mathrm{mg} \backslash \mathrm{L})$ in tap water which remains motionless in plumbing system for following periods ( one hours, 3 hours, 6 hours, 12 hours, 24 hours, 7 days and 14 days) are ( $1,2.2,4,5.3,7.5,10$ and $16 \mathrm{mg} \backslash \mathrm{L}) \&(0.3,0.5,0.8,1,2.5$ , $3,3.8 \mathrm{mg} / \mathrm{L}$ lead ) respectively ,because the concentration of copper are high and do not give a accurate results to overcome this problem ,the solutions are diluted many times then multiple the results by the time of dilutions also the values of absorptions are converted to analytical concentrations by using the Beerlambert law in case of lead from these results it is clear that a high levels of copper occur if tap water comes in contact with copper-lead plumbing and copper lead-containing fixtures in the water distribution system. If tap water remains motionless in the plumbing system for some time, copper levels may exceed the normal level, the level of copper and lead in drinking water increases with the corrosivity of the water and the length of time it remains in contact with the plumbing.

These amounts of copper are believed according to World Health Organization (WHO) to have given rise to the symptoms of chemical food poisoning precipitated by the ingestion of alcohol on an empty stomach. Also children under one year of age are more sensitive to copper than adults[21]. Long-term exposure (more than 14 days) to copper in drinking water which is much higher than 1,000 ug/I has been found to cause kidney and liver damage in infants. generally the health-based guideline values for copper and lead in drinking water is the concentration of (1.0) $\mathrm{mglL}$ and( $0.05) \mathrm{mg} L \mathrm{~L}$ respectively proposed by World Health Organization (WHO) 
and the US Environmental Protection Agency ( EPA ) [ 22,23 ], in addition to Iraqi standard No. (417) for drinking water.

The maxium acceptable level of lead in drinking water in Baghdad area has been established in this work.

\section{Conclusions:}

The present research indicates that the amount of the copper which was found in drinking water of plumbing system in Baghdad region are believed according to World Health Organization ( WHO ) to have given rise to the symptoms of chemical food poisoning precipitated by the ingestion of alcohol on an empty stomach. Also children under one year of age are more sensitive to copper than adults. Long-term exposure (more than 14 days) to copper in drinking water has been found to cause kidney and liver damage in infants. Amounts of lead in drinking water in Baghdad area in this work according to (WHO) is in anormal level .

\section{Recommendation:}

Avoiding drinking or cooking with water that has been in contact with house plumbing for more than six hours and using bottled water. Particularly if it will be used by young children as drinking water, or for making infant formula and finally using plastic tubes instead of steels alloys tubes which are used usually in plumbing system can be recommondated as a simple way for reducing exposure the drinking water to copper and lead .

\section{References:}

1. Gulson, A.J. ; Law, M.J ; Karen. J.M. 2011. Effect of plumbing on lead content of drinking water and contribution to lead body burn. The science of the total enviroment. New York. p.159.

2. Gholivand, M. B.; Mozaffari, Y.; Sobhani, S. and Ghasemi, J. 2008.

Simultaneous spectrophotometric determination of trace amounts of cobalt, nickel, and copper using the partial leastsquares method after the preconcentration of their 2aminocyclopentene-1-

dithiocarboxylate complexes on microcrystalline naphthalene Journal of Analytical Chemistry. 5(3).232-38.

3. Sunitha, B. M and Ajai K. P. 2007.Micro wave assisted spectrophotometric method for the determination of copper using leucocrystal violet Bull. Chem. Soc. Ethiop.. 21(1). 129-134.

4. Shpigun, L.; Shushenachev, Y. and Kamilova, P.2007.

Spectrophotometric determination of coppr (II) and zinc (II) based on their kinetic separation in flowinjection systems. Journal of Analytical Chemistry.. 62 (7). 62331.

5. Fu, D. and Yuan, D.2006. Spectrophotometric determination of trace copper in water samples with thiomichlersketone Spectrochim. Acta. A. Mol. Biomol. Spectrosc.11(3).21-28.

6. Ghazy, S. E.; El-Shazly R. M.; ElShahawi, M. S.; Al-Hazmi, G. A. A.; and El-Asmy, A. A. 2006.Spectrophotometric

Determination of Copper (II) in Natural Waters Using

Acetophenone-pchlorophenylthiosemicarbazone Journal of the Iranian Chemical Society . 3(2).140-50.

7. Massoud A .D and Nejati- Y . S. 2006. Spectrophotometric determination of trace $\mathrm{Cu}$ (II) ion based on complexation with 
Anthraquinine derivative Anal Sci.. 22(3). 617-619.

8. Shishehbore M. R.; Nasirizadeh N. K.; Haji Shabni A. M.J.and Tabatabaee, M. F. 2006 .Spectrophotometric determination of trace copper after Precocentration with 1,5-Diphenylcarbazone on Microcrystalline 11. Naphthalene Canadian Journal of Analytical Science and Spectroscopy. 50(1). 130-34.

9. Subramanyam S.; Kumar, J. R.; Reddy, K.J., and Reddy, A. V. 2005. Development of an Extractive Spectrophotometric Method for the Determination of Copper(II) in Leafy Vegetable and Pharmaceutical Samples Using Pyridoxal-4-phenyl-3thiosemicarbazone (PPT) J. Agric. Food Chem. 53 (14). 5492-98.

10. Sandra, V. M.; Jorge, L. W.; Caroline, D.K.; Lucas, C.M.; Marina, T.H.; Marcia, R.R.; Edílson., V.B and Eder, C.J .2005 Use of 1,3-diaminepropane-3propyl grafted onto a silica gel as a sorbent for flow-injection spectrophotometric determination of copper (II) in digests of biological materials and natural waters Spectrochimica Acta Part A: Molecular and Biomolecular Spectroscopy.. 62(13).398-406 .

11. Bin Du - Bin Du, L. Y.; Ding, Y. D.; Caihong.K.M. and Qin WeiQin,M . 2005. Catalytic Kinetic Spectrophotometric Determination of Trace Amounts of Copper (II) in Biosamples using Tween-20 Microemulsion as Sensitizer. Analytical Letters J. 38(4).711 -725.

12. Asan, A.M and Isildak, I.H.2003. A simple and selective flow-injection spectrophotometric determination of copper (II) by using acetylsalicylhydroxamic acid Talanta . 60(3).861-66.
13. Ohno, S.V.; Teshima, N.M.; Zhang, H.H, and Sakai, T.Y. 2003. Utilization of activating and masking effects by ligands for highly selective catalytic spectrophotometric determination of copper and iron in natural waters Tanata . 60(5).1177-85.

14. Thipyapong, K.R and Suksai, C.T 2003. Spectrophotometric Determination of Copper (II) Using Diamine-Dioxime Derivative Bulletin of the Korean Chemical Society. 24(12).1767-70.

15. Cesur, H.J and Bati, B.K. 2002. Solid-Phase Extraction of copper with lead 4benzylpiperidithiocabamate on Microcrystalline Naphthlene and its spectrophotometric determination. Turkish Journal of Chemistry. 26(2) .599-606 .

16. Pourreza, N.I and Behpour, M.V. 1998. Catalytic Spectrophotometric Determination of Trace Amounts of Copper (II) Based on the Oxidation of 2, 4Dinitrophenylhydrazone-1, 2naphtoquinone-4-sulfonic Acid by Hydrogen Peroxide Anal. Sci. 14(5). 9-16. UK .

17. Sandell, E. B. 2004. Colorimetric determination of trace of metals. 3rd ed. Interscience.New York.

18. Welz,N. B.; Yin X. F. and Sperling, M.F. 1992 .Time-based and volume-based sampling for flow-injection on-line sorbent extraction graphite furnace atomic absorption spectrometry Analytical Chimica Acta. 261(4). 477-485.

19. Greenberg, E. A.; Clesceri, S. L. and Eaton, D. A. (eds). 1992 Standard Methods for the Examination of Water and Wastewater. $18^{\text {th }}$ ed. Americation Public Health Association. Washington D.C,13. 
20. Rekhai, D.E.; Suvardhani, K.H .; Kumar, K.S.; Reddyprasad, P.J .; Jayaraj B.B and Chiranjeevi, P.N 2007.

Extractive spectrophotometric determination of hydroxybenzaldehyde-4-

bromophenyl hydrazone (3, 4MHBBPH) J. Serb. Chem. Soc. 72(3). 3299-310.
21. World Health Organization. International standards water. Geneva:WHO, 1958.

22. World Health Organization. Guidelines for drinking-water quality.Vol 1, Recommendations, Geneva:WHO, 1984.

23. Peter, M .M ; Poger, S . Ron, D.E, 2011. Lead contaimation in drinking water, Chem. Soc. in Australia . 14(7).310-317.

\title{
تعيين النحاس والرصاص ودراسة التأثير السمي لها في مياه الثرب في بغداد

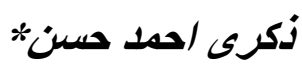 \\ *فرع العلوم الاساسية ، كلية طب الاسنان ، الجامعة المستتصرية
}

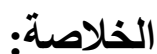

الهدف من هذه الدراسة هو قياس تركيز النحاس والرصاص ( ملغم التر ) في ماء الثرب بواسطة طريقة

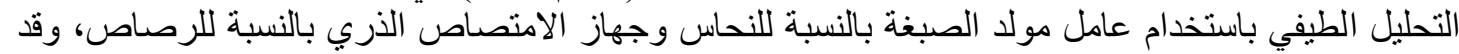

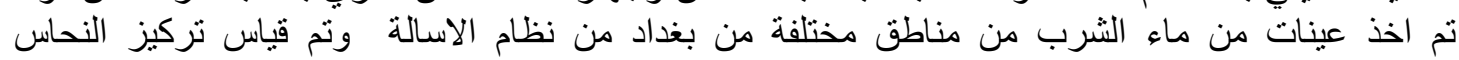

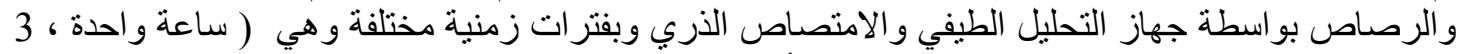

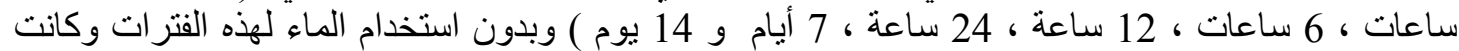

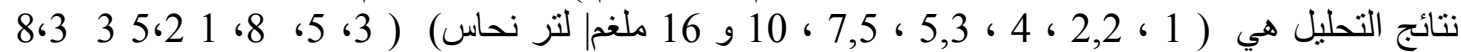

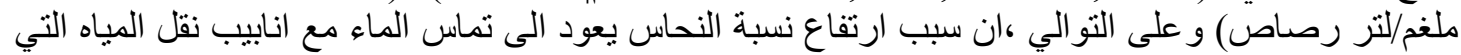

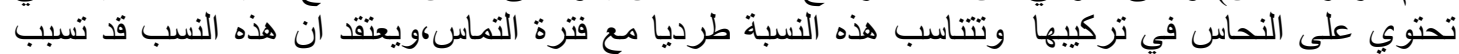

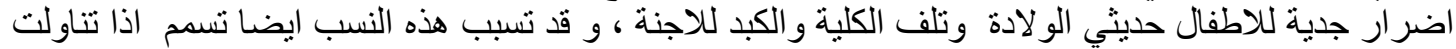

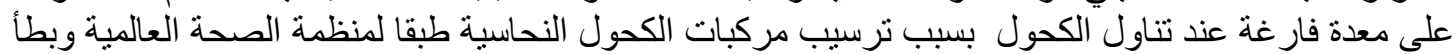

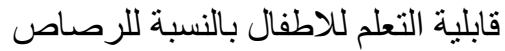

